\title{
Research on the Development of Internal Control Environment Theory and its Constituent Elements of Enterprises in China
}

\author{
Jing LIU ${ }^{1}$, Panting NIE ${ }^{2, a}$, Lijia HUANG ${ }^{3}$ \\ 1 Jiangxi Normal University Business College, China \\ 2 Jiangxi Normal University Business College, China \\ 3 Jiangxi Normal University Science and Technology College, China \\ a jxsdjh@vip.sina.com
}

Keyword: Control enviroment; Internal control; enterprises

\begin{abstract}
The control environment is a very important element of the internal control of enterprises. It plays a vital role in the implementation of enterprises internal control and has a profound impact on the survival and development of enterprises.

\section{Introduction}

With the promulgation of a series of laws and regulations on internal control, enterprises have paid more and more attention to the construction of internal control environment.Many enterprises have not seriously constructed the internal control environment of enterprises, and a series of problems have emerged. These problems all indicate that there are major defects in the internal control environment of enterprises. Therefore, enterprises must strengthen the construction of the internal control environment, so as to better improve the operating efficiency of the enterprise.
\end{abstract}

\section{Theoretical Development of the Internal Control Environment of Enterprises}

\subsection{Inoculation Stage}

The concept of internal containment was first proposed to protect the security of cash and assets and to ensure the accuracy of book records. The main idea of internal containment is to prohibit a person or a functional department from having multiple roles. In the internal control, more performance is the budding stage of internal containment, and the control environment is correspondingly in the gestation stage. During this period, most of the focus of the enterprise is on the control of simple business, and subjectively, the control environment is not formed. The consciousness of developing a very important factor, but objectively has a demand for the control environment.

\subsection{Budding Stage}

In 1949, the Auditing Procedures Committee of the American Institute of Certified Public Accountants (AICPA) published a study on the "Internal Control, Coordination System Elements and Their Importance to Management and Certified Public Accountants." This report first proposed the authority of internal control. Sexual definition, that is, "internal control is an organizational plan and mutual support that is formulated to protect property, protect the correctness and integrity of accounting materials, improve the efficiency of business operations, and promote the implementation of policies formulated by various management departments. Methods and measures."In 1958, in the "Audit Procedure Announcement No. 29", CAP divided internal control into accounting control and management control, and gradually formed an institutionalized internal control environment. The internal control environment gradually sprouted. 


\subsection{Clear Stage}

With the increasing research on internal control, the American Institute of Certified Public Accountants issued the Auditing Standards Bulletin No. 55 in 1988 (SAS NO. 55). In SAS No. 55, internal control is basically considered to be an organic whole structure. This overall structure includes various policies and procedures that need to be established and implemented to achieve the goals set by the enterprise, including: control environment, accounting system, control program.

\subsection{Attention Stage}

The COSO Committee issued the Internal Control-Integration Framework in 1992. The 1992 COSO Report proposed five elements of internal control: control environment, risk asses, control activities, information and communication, and monitoring. These five elements are the perfect development of the original three elements, and a new theoretical breakthrough on the basis of the original elements. The COSO Internal Control Framework Report of 1992 made a detailed explanation of the composition of the control environment, affirmed the basic role of the internal control environment in the internal control system, and emphasized the influence of the internal control environment on other internal control factors.

\subsection{Emphasis Stage}

In 2004, the COSO Committee added the concept of risk management to the original internal control framework, and also expanded the original five elements into eight new elements. The internal environmental factors of COSO in 2004 include the company's risk management philosophy, risk capacity, supervision of the board of directors, integrity of employees within the organization, ethical values and talents, management style and business philosophy, management power and responsibilities, organization and development of employees Ways, attention and guidance given by the board of directors.

\section{The Main Components of the Internal Control Environment of China's Enterprises}

\subsection{Corporate Governance Structure}

Corporate governance structure refers to a set of institutional arrangements for the supervision, incentive, control and coordination of the company's operations and performance management in order to effectively allocate resources. It reflects the relationship between the various players who determine the direction and performance of the company. Usually the corporate governance structure is a certain interrelationship framework formed by the owner, the board of directors and the executive manager. enterprises are limited by technology and scale. They are generally composed of partners and subordinate employees. They do not have a sound governance structure and affect the effective implementation of internal control.

\subsection{Institutional Setting and Distribution of Powers and Responsibilities}

Institutional setup and assignment of authority and responsibility refer to the establishment of the organizational structure of enterprises and the distribution and authorization of responsibilities. These two aspects are important factors influencing the internal control of enterprises. The organizational structure is a structural system formed by all members of the enterprise to achieve the common goal of the enterprise, to carry out division of labor and cooperation in the management work, and to form the scope of duties, responsibilities and rights. Organizations play a "skeleton" role in the construction of internal control, which is suitable for the organization of enterprises.

\subsection{Human Resources}

Human resources are people employed by companies for their daily business activities, including managers and basic employees. People are one of the most important factors affecting the quality of internal control of enterprises in the internal control environment, because the establishment, 
implementation, supervision and feedback of the internal control system of the enterprise are all implemented by people. If the employees employed by the company do not have the professional knowledge and professional ethics that match their profession, then the internal control system will not work well.

\subsection{Internal Audit}

Internal audit as a factor of internal control environment, the main purpose is to ensure that enterprises can conduct business in compliance with laws and regulations in the course of business operations and ensure the implementation of decision-making by superior management, thereby protecting the security of corporate assets and ensuring the recording of account books. Correctness and completeness.

\subsection{Company Culture}

Corporate culture is a cultural concept formed by a company in the process of development. It is a measure of value, but this measure of value will influence the employee's code of conduct and determine the way employees behave. The stronger the corporate culture and the stronger the cohesiveness, the stronger the sense of internal control in the organization.It will lead to the lack of cohesiveness and ultimately the lack of competitiveness, which will make the internal control system and activities of the company lose vitality and ultimately affect the effectiveness of the internal control of the enterprise.

\section{The Influence of Internal Environment of Internal Control of China's Small and Medium Enterprises on the Effectiveness of Internal Control}

The internal control environment is the basis of other elements of internal control. Without an effective internal control environment, other elements cannot form effective internal control regardless of quality. The perfect internal control environment is the guarantee of internal control effectiveness, and effective internal control can promote the continuous improvement of internal control environment and help enterprises achieve corporate goals. It is believed that to establish a high-quality and efficient internal control system must have a good internal control environment. The rationality of the internal control environment construction can determine the role of other elements in other control systems.It directly affects the effectiveness of internal control implementation.

\section{Conclusion}

The internal control and control environment is the basis for the internal control of enterprises. The internal control and control environment is the basis for the internal control. The effectiveness and soundness of the internal control environment directly affects the effectiveness and soundness of the internal control. Therefore, it is very important to carry out a comprehensive study on the internal control environment of enterprises. Based on the definition of the internal control environment of the enterprise, this paper analyzes the main influencing factors of the internal control environment of enterprises and the impact of the internal control environment on the effectiveness of enterprises internal control, in order to further the overall internal control level of enterprises in China. Effectively promote contributions and provide impetus for the sound development of enterprises in China.

\section{Acknowledgements}

This paper is one of the research results of The Construction Evaluation Model and Analysis of Influencing Factors of Enterprise Group Performance under Strategic Orientation in The Research Project of the Science and Technology of Jiangxi Provincial Department of Education. It is funded 
by The Special Fund for the Visiting Scholars of the Young and Middle-aged Teacher Development Program in Jiangxi Ordinary Universities.

\section{References}

[1] Jin Ma, Qiao Pengcheng. A Literature Review of Enterprise Internal Control Environment Research, Commercial Accounting, vol.02, pp: 55-57, 2016.

[2] Yanbin Guo. Problems in the internal control environment of enterprises and countermeasures, Modern Economic Information, vol. 20, pp. 89-89, 2017.

[3] Wei Wu. Research on the Influence of Enterprise Internal Control Environment, Knowledge Economy, vol. 07, pp: 94-94, 2017. 